\title{
Study on Wind Environment Influencing Factors and Layout of Urban Ordinary Residence
}

\author{
Xiang CHEN ${ }^{1}$ and Xiang DUAN ${ }^{2}$ \\ Civil Engineering and Architecture Institute, Wuhan Polytechnic University, Wuhan, \\ Hubei, China
}

\begin{abstract}
In the architectural planning and design, the commonly used architectural layout forms are determinant, diagonal, etc. Because of its centralized and symmetrical layout form, determinant architecture has been widely used in urban architectural design. Due to the high density of multi span buildings, the ventilation effect is not good, so this paper mainly studies the influence of multi span building layout on the wind field of urban ordinary residence. In order to optimize the wind environment of the building, a 7-story residential area was modeled and calculated by CFD. Through the analysis of wind field characteristics at different building heights, the results show that the total wind speed in $\mathrm{Z}$ direction of the building is the smallest, about $3.354 \mathrm{~m} / \mathrm{s}$; At the same time, the overall wind pressure values are within $5 \mathrm{~Pa}$ of the standard wind pressure difference, but we still need to pay close attention to the possible environmental impact at the outlet of the determinant residence.
\end{abstract}

Keywords. Wind environment, urban ordinary residence, building heights

\section{Introduction}

In architectural planning and design, the common forms of architectural layout are determinant, enclosed, staggered and oblique. The so-called determinant layout means that the spatial arrangement of buildings in the site area is relatively fixed and concentrated, and the building spacing is basically relatively fixed on the basis of meeting the relevant building fire prevention and other specifications in China [1-2].

Because the arrangement of determinant architecture is relatively concentrated in space, it can show a symmetrical beauty in form. At the same time, among the buildings, the determinant is arranged in parallel with a certain distance. From the overall perspective, the spatial arrangement of this type of layout is a neat arrangement pattern [3-5].

1 Corresponding Author, Xiang CHEN, Civil Engineering and Architecture Institute, Wuhan Polytechnic University, Wuhan, Hubei, China; Email: 3180353209@qq.com.

2 Corresponding Author, Xiang DUAN, Civil Engineering and Architecture Institute, Wuhan Polytechnic University, Wuhan, Hubei, China; Email: 287264@qq.com. 


\section{Selection of Calculation Area of Model}

It is calculated that the residential area is an ordinary building, $450 \mathrm{~m}$ long in east-west direction ( $\mathrm{x}$ direction) and $200 \mathrm{~m}$ long in north-south direction (Y direction). The average height of the residential area in Wuhan is $7 \times 3=21 \mathrm{~m}$; And the $\mathrm{Z}$ direction of the calculation domain is about 5 times of the average height of the residential area, that is, $100 \mathrm{~m}$. Therefore, the calculation domain is $450 \mathrm{~m} \times 200 \mathrm{~m} \times 100 \mathrm{~m}$. There are 16 residential buildings in the residential area [6-8]. The plane distribution form of No.1-16 residential buildings is determinant building layout. The geometric dimensions of the model are shown in figure 1 below.

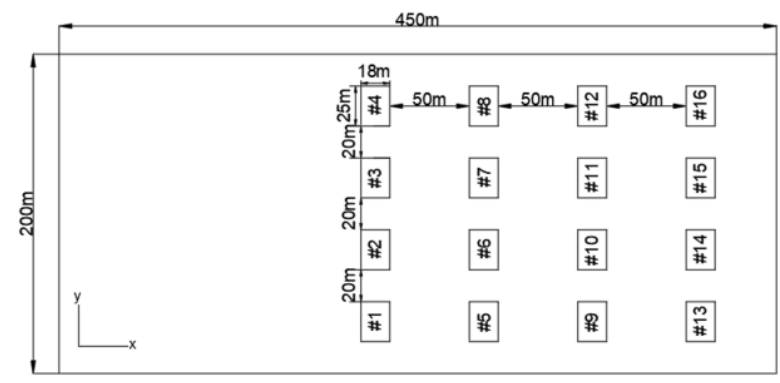

Figure 1. Geometric dimension of determinant model.

\section{Creating Models to Calculate Boundary Conditions}

The average outdoor wind speed in Wuhan in winter can be selected as the inlet velocity condition of the model. Considering the actual situation and the research purpose of this subject, the following table 1 is proposed as the simulation boundary condition of the determinant building complex:

Table 1. Model boundary conditions.

\begin{tabular}{llll}
\hline \multicolumn{4}{l}{ Number Model area } \\
\hline 1 & Boundary type Boundary value \\
2 & Wall & Velocity-inlet & $3.0 \mathrm{~m} / \mathrm{s}$ \\
3 & Outlet & Outflow & - \\
\hline
\end{tabular}

After setting the above boundary conditions of ICEM, they are shown in figures $2 \mathrm{a}-2 \mathrm{~d}$.

The calculation boundary is set to simulate the wind field of determinant residential buildings in ideal state; The simplified geometric model is adopted without considering the external factors, and no slip boundary is selected on the model wall [9].

\section{Model Mesh Generation}

In view of the accuracy of computer simulation, the running speed and the computer memory space that may be occupied, the global size of the calculation model grid is determined to be 5 (the default grid size unit in ICEM is $\mathrm{mm}$ ), the scale factor is set to 
1, and the widely used unstructured tetrahedral grid is selected as the grid type, The grid number shown in table 2 below can be obtained.

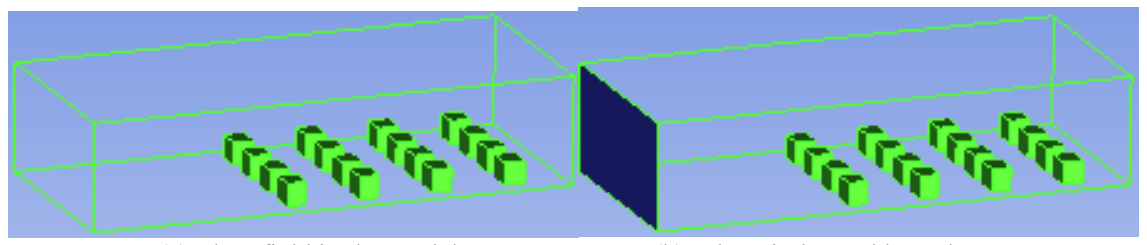

(a) Flow field in the model

(b) Inlet wind speed boundary

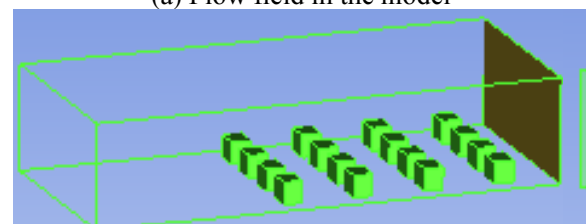

(c) The outlet pressure boundary

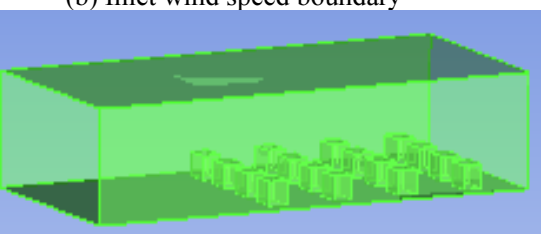

(d) No slip boundary

Figure 2. Model calculation boundary.

Table 2. Grid number of determinant layout model.

\begin{tabular}{llll}
\hline Type of boundary Entrance boundary & Wall boundary & Export boundary \\
\hline Number of grids & 1738 & 24354 & 1706 \\
Type of grids & linear & triangle & quadrilateral \\
Number of grids & 1582 & 32370 & 1006837 \\
Sum up & The total number of cells is & 175040, and the total number of grids is 1040925 \\
\hline
\end{tabular}

\section{Grid Checking and Flow Field Calculation Based on Fluent}

Considering the influence of the boundary effect on the fluid calculation of the model, the model is densified near the wall; For the part outside the determinant house, the accuracy of the model is determined, and the part far away from the wall is processed according to the automatic mesh. And the meshings are to be shown in figures $3 a-3 c$.

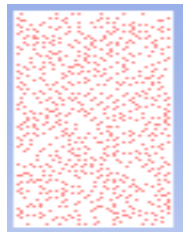

(a) Entrance grid

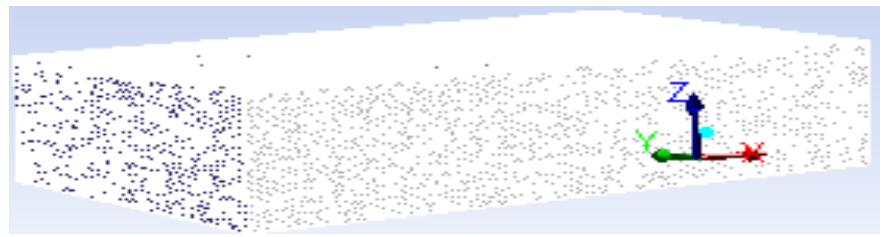

(b) wall grid

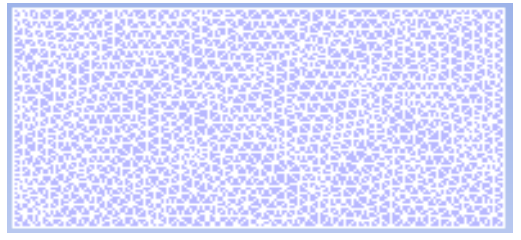

(c) exit grid

Figure 3. The model boundary grid in fluent. 
The parameters of this model are shown in table 3.

Table 3. Material parameters.

\begin{tabular}{|c|c|c|c|c|c|}
\hline Part & Material properties & Main material & 1 Density $\left(\mathrm{kg} / \mathrm{m}^{3}\right)$ & Velocity $(\mathrm{m} / \mathrm{s})$ & Ground roughness coefficient \\
\hline Wind & fluid & air & 1.225 & 3.0 & - \\
\hline building & s solid & concrete & 2500 & - & 0.22 \\
\hline
\end{tabular}

\section{Simulation Analysis of Determinant Model}

At the same time, the cloud image and data obtained by fluent simulation are imported into the professional CFD post-processing software CFD post to show the results of wind speed, wind pressure cloud image and wind speed vector image as shown in figures 4-6 respectively.

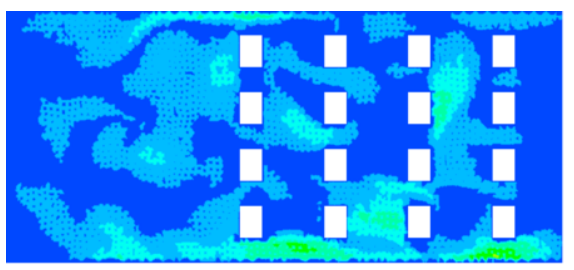

$\begin{array}{llllllllll}0.000 & 0.373 & 0.745 & 1.118 & 1.491 & 1.863 & 2.236 & 2.609 & 2.981 & 3.354\end{array}$

(a) $\mathrm{z}=1.5 \mathrm{~m}$

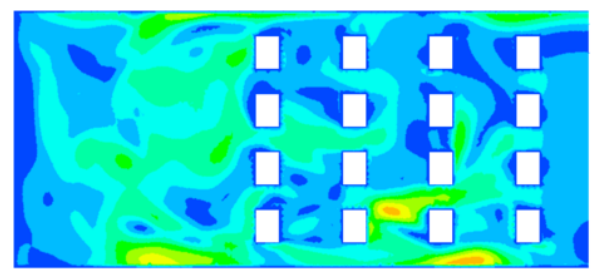

$$
\text { (c) } \mathrm{z}=15 \mathrm{~m}
$$

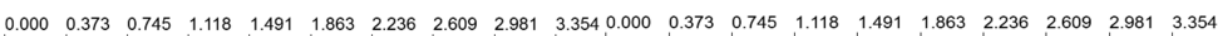

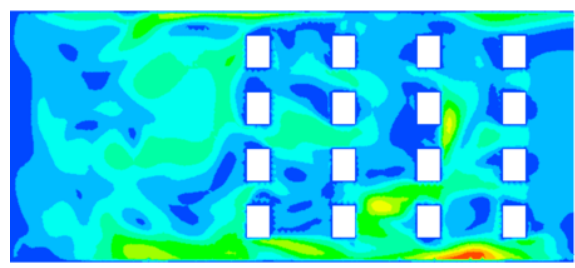

$\begin{array}{llllllllll}540.000 & 0.373 & 0.745 & 1.118 & 1.491 & 1.863 & 2.236 & 2.609 & 2.981 & 3.354\end{array}$

(b) $\mathrm{z}=10 \mathrm{~m}$

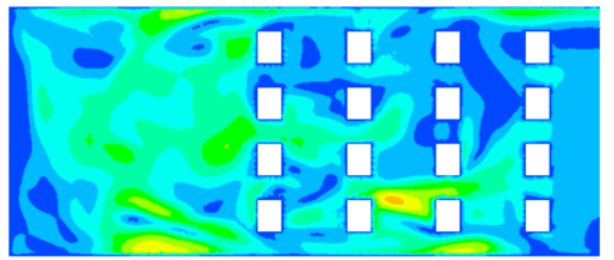

(d) $z=20 \mathrm{~m}$

Figure 4. Wind speed cloud chart of determinant buildings at different heights.

As shown in figure 4 above, the entrance wind speed at the pedestrian height is about $0.373 \mathrm{~m} / \mathrm{s}$, which meets the requirements of human comfort; With the increase of building height, the average wind speed in the region is basically stable in the range of $0.745-2.236 \mathrm{~m} / \mathrm{s}$, not more than $3 \mathrm{~m} / \mathrm{s}$. As shown in figures $5 \mathrm{a}-5 \mathrm{~d}$, the wind pressure changes of determinant buildings at different Z-direction heights are as follows:

As shown in figure 5 above, the negative wind pressure at the entrance gradually transits from $-3.221 \mathrm{pa}$ (pedestrian height) to $-1.996 \mathrm{pa}$ and then to $0.543 \mathrm{pa}$ with the height of $Z$ direction; In the calculation domain, a negative pressure zone appeared near the No. 9 building, which decreased after $z=15 \mathrm{~m}$. The four figures shown in figure 6 below show the wind direction of the determinant building at different $\mathrm{z}$-height.

Figure 6 shows that the wind direction at the pedestrian height changes uniformly without overall difference; At $\mathrm{z}=10,15$ or $20 \mathrm{~m}$, there is a certain wind direction 
disturbance around buildings 9-16, and the disturbance wind speed is about $2.307-3.460 \mathrm{~m} / \mathrm{s}$.
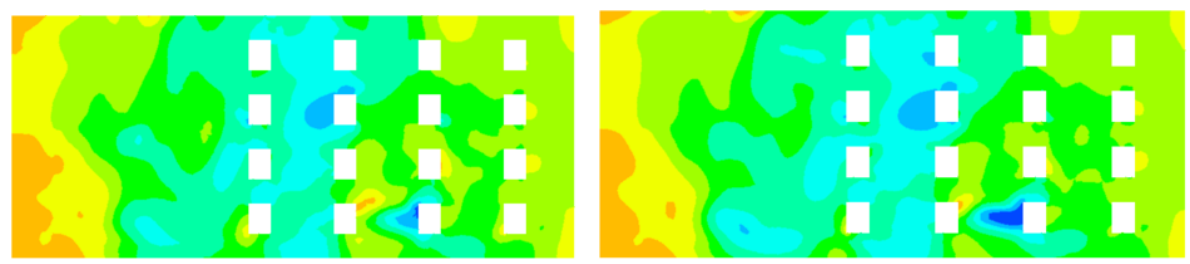

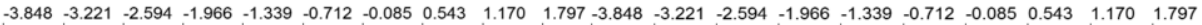

(a) $\mathrm{z}=1.5 \mathrm{~m}$

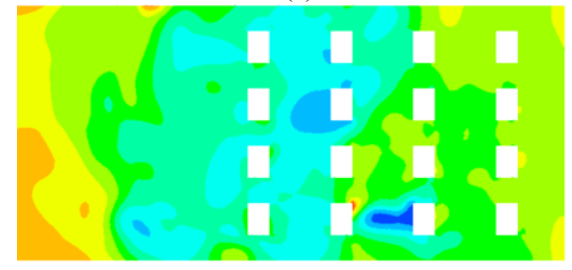

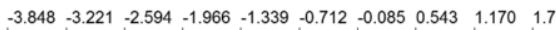

(b) $\mathrm{z}=10 \mathrm{~m}$

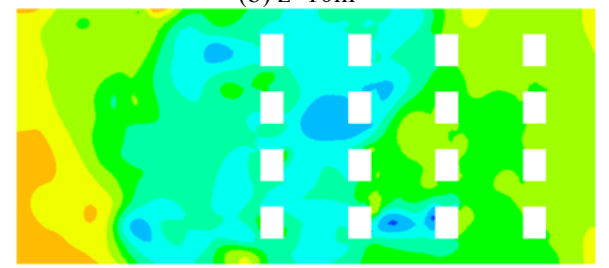

(d) $z=20 m$

Figure 5. Wind pressure nephogram of determinant buildings at different heights.
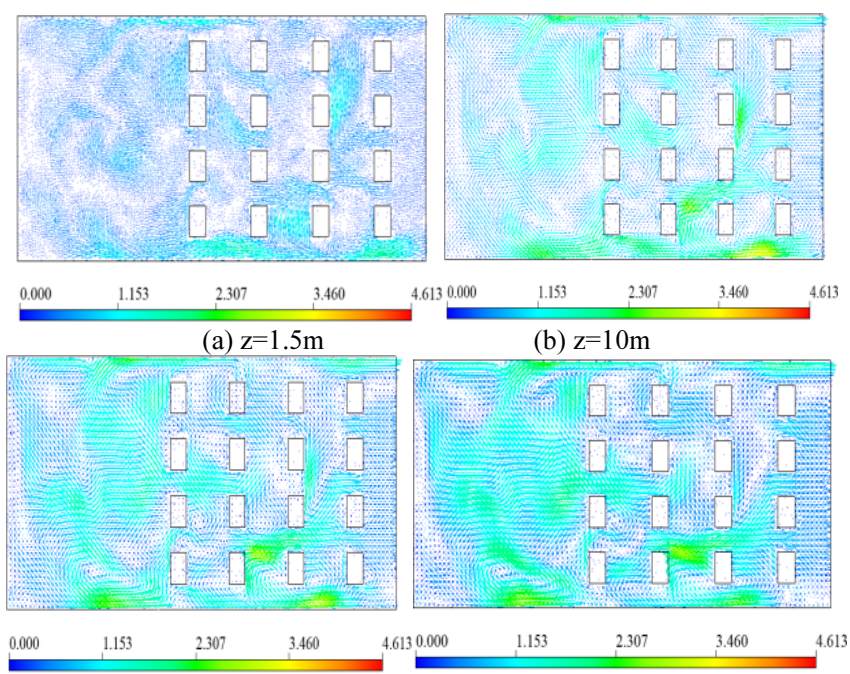

(c) $\mathrm{z}=15 \mathrm{~m}$

(d) $\mathrm{z}=20 \mathrm{~m}$

Figure 6. Wind speed vector diagram of determinant buildings at different heights.

\section{Conclusion}

To sum up, the numerical simulation of the 7-story ordinary residence is carried out based on CFD:

(1) When the height of determinant building is between $0-20 \mathrm{~m}$, the wind 
parameters are smaller and the overall mean square deviation is smaller, which is more stable; Among them, the wind pressure difference between the windward side and the leeward side is still within the acceptable range of the Chinese code, that is, $5 \mathrm{~Pa} \mathrm{[10]}$.

The overall wind speed in the calculation area is within $3 \mathrm{~m} / \mathrm{s}$, and the peak wind speed is most likely to appear on the windward side of the air inlet, which should be improved in the actual design.

(2) The wind speed value of determinant building in different altitude is different; which may lead to the decrease of living comfort; At the same time, the wind pressure difference is small and within the specified value.

\section{Acknowledgments}

First of all, I would like to offer my most sincere thanks to my instructor, Professor Duan Xiang. Thank you for your kind guidance.

Secondly, I would like to thank all the students who helped me during my writing. Thank you for your help so that I will not feel lonely in the process of completing the paper.

And in the end, all of what our team have achieved is due to the strong foundations of Funds. Those are two parts for each one. One is for General project of Hubei Social Science Fund (2018q124) - Research on the planning of old communities based on public participation. The other fund is Science and technology plan of Wuhan Urban Construction Commission (201739)-Research on upgrading function of old communities in Wuhan.

\section{Reference}

[1] Stathopoulos T 1996 Computer simulation of wind environmental conditions around buildings Engineering Structures 18 (11) 876-885.

[2] Yamada M, Uematsu Y and Sasaki R 1996 A visual technique for the evaluation of the pedestrian-level wind environment around buildings by using infrared thermography Journal of Wind Engineering \& Industrial Aerodynamics.

[3] Bonser S, Hughes B R and Calautit J K 2020 Investigation of the impact of roof configurations on the wind and thermal environment in football stadiums in hot climates International Journal of Ventilation 19 (4) 260.

[4] Dutt A J 1991 Wind flow in an urban environment Environmental Monitoring and Assessment 19 (1-3) 495-506.

[5] Loubser L 1992 The influence of buildings on ground level wind conditions Town and Regional Planning (32) 4-12.

[6] Lam K M 1992 Wind environment around the base of a tall building with a permeable intermediate floor Journal of Wind Engineering and Industrial Aerodynamics 44 (1-3) 2313-2314.

[7] To A P and Lam K M 1995 Evaluation of pedestrian-level wind environment around a row of tall buildings using a quartile-level wind speed descriptor Journal of Wind Engineering \& Industrial Aerodynamics $\mathbf{5 4}$ 527-541.

[8] Sasaki R, Uematsu Y, Yamada M, et al. 1997 Application of infrared thermography and a knowledge-based system to the evaluation of the pedestrian-level wind environment around buildings Journal of Wind Engineering \& Industrial Aerodynamics 67 873-883.

[9] Visser G T, Folkers C J and Weenk A 2000 KnoWind: A database-oriented approach to determine the pedestrian level wind environment around buildings Journal of Wind Engineering \& Industrial Aerodynamics 87 (2) 287-299.

[10] Yoshie R, Mochida A, Tominaga Y, et al. 2007 Cooperative project for CFD prediction of pedestrian wind environment in the Architectural Institute of Japan Journal of Wind Engineering \& Industrial Aerodynamics 95 (9) 1551. 